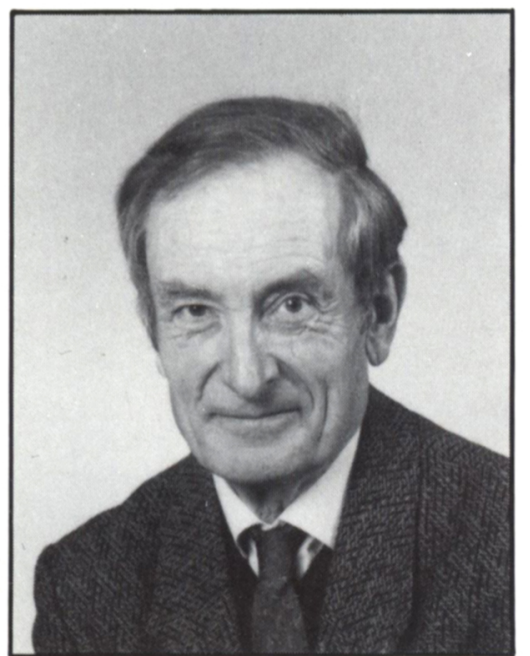

Jacques Friedel

Jacques Friedel, head of the Physics Department at the University of Paris in Orsay, will receive the 1988 Von Hippel Award from the Materials Research Society during a ceremony at the 1988 MRS Fall Meeting in Boston. The award, the Society's highest honor, will be given in recognition of his many major contributions to a wide range of fields within the domain of condensed matter sciences which have profoundly influenced-both theoretically and experimentally-advances ranging from the quantum theory of solids, materials science, and metallurgy to chemistry.

Professor Friedel's research has been primarily directed toward basic and fundamental questions rather than specialized areas. As a result, his solutions have influenced virtually every line of condensed matter research over the past 30 years, including dislocations, creep, internal friction and work-hardening of metals, ferromagnetism, superconductivity, the electronic structure of metals and alloys, liquid crystals, and cluster physics.

The hallmark of his work encompasses pioneering contributions to the understanding of behavior of dislocations and strength of materials, electron theory of metals, and the properties of alloys. By 1954, he had formulated the ideas that have become known as the Friedel sum rule and Friedel oscillations, as well as others, which laid the foundations for subsequent developments in the field.

\title{
Jacques Friedel Named 1988 Von Hippel Award Recipient
}

\author{
Friedel has made major contributions to a wide range \\ of fields within the domain of condensed matter sciences \\ which have profoundly influenced...theoretically and \\ experimentally...advances ranging from the quantum theory \\ of solids, materials science, and metallurgy to chemistry.
}

Around this time, he developed the concepts of virtual bound state and magnetic moments. His early papers on these topics, many co-authored with A. Blandin, form a classic body of work in solid state physics.

The list of his other notable achievements includes the development of the concept of spin glass; a real-space approach to calculating the electronic structure of materials that lack translational symmetry; the Friedel model for oriented cross-slip of dislocations; the dissociation of dislocations into disclinations; and the description of work-hardening in metals through the interaction of dislocations with a random array of obstacles. His 1956 text, Les Dislocations, is also a widely read classic that has been translated into several languages.

\section{Friedel was instrumental in reestablishing the European physics community following World War II.}

Professor Friedel was instrumental in reestablishing the European physics community following World War II. He ensured that the applied side of materials science would not follow the pre-1939 metallurgical tradition, but instead fully incorporated the developments of dislocations and electronic structure. That he introduced these concepts in the 1950s in France-but that they were not fully adopted in other parts of Europe until the 1970 s-attests to his vision.

The Laboratory of Solid State Physics, which Friedel established and which he is still associated with at the University of
Paris, quickly gained a high international reputation, largely as a result of the toplevel scientists attracted to the institution by Friedel. He brought together researchers from different laboratories and ideas from different disciplines, and fostered the linkage of theoreticians and experimentalists. The majority of France's solid state physicists completed their theses with Friedel or his students, and many have gone on to establish themselves as noted authorities in their own specialties.

A strong proponent of the importance of the fundamental sciences, Friedel has been actively involved in the development of science policy in France, and has served as president of the European Physical Society.

Professor Friedel is a member of the French Academy of Sciences, Officer of the Légion d'Honneur, Commandeur of the Ordre du Mérite, and an honorary member of numerous foreign scientific societies. He has been awarded an Honorary Doctorate from the Ecole Polytechnique Fédérale of Lausanne (Switzerland), the Prix Ancel, Robin et Holweck of the French Physical Society, the Gold Medal of the C.N.R.S., the Prix d'Aumale and the Prix Cognac Jay of the French Academy of Sciences, the Rosenhain Medal of the Institute of Metals in London, the HumeRothery Award of the American Institute of Mining, Metallurgical, and Petroleum Engineers, the Dannie Heineman Preis of the Göttingen Academy of Sciences, and the Acta Metallurgica Gold Medal.

Following presentation of the 1988 Von Hippel Award to Professor Friedel by MRS President John Baglin, Professor Friedel will provide a lecture highlighting aspects of his research work. The ceremony and lecture will be held Wednesday, November 30 at 6:00 p.m. in the America Ballroom, Westin Hotel, Boston. 


\section{The Von Hippel Award}

The Von Hippel Award is the Materials Research Society's most prestigious award. It is presented annually to the living scientist who, in the Society's estimation, best exemplifies throughout a career the originality, brilliance of intellect, and diligence of purpose that are the hallmark of science at its best; who adheres to the strictest ethical standards and highest code of professional integrity; and whose vision transcends conventional disciplines, as does the science of materials itself.

The award consists of a synthetic ruby crystal suitably mounted, a cash honorarium, and a lifetime membership in the Society. It is named for Arthur Robert von Hippel, emeritus professor of the Massachusetts Institute of Technology, who was also its first recipient.

The MRS Awards Committee solicits nominations annually from among the membership and elsewhere in the community of materials scientists. The nominees are evaluated against the Society's criteria, rather than against each other. From among the candidates it has reviewed, the Awards Committee puts forward the names of the principal contenders for the honor. The nominees are considered in confidence by the Council of the Society. The Council, representative of the many disciplines and institutions within MRS, makes the final decision by a majority vote.

\section{Previous Von Hippel Award Recipients}

1977

Arthur R. von Hippel

Emeritus Professor, Massachusetts Institute of Technology

1978

William O. Baker

Emeritus Chairman of the Board, Bell Laboratories

1979

Gordon McKay Professor of Applied Physics, Harvard University

\section{0}

W. Conyers Herring

Professor of Applied Physics, Stanford University

\section{1}

James W. Mayer

Francis Norwood Bard Professor of Materials Science and Engineering, Cornell University

\section{2}

Clarence M. Zener

Emeritus University Professor,

Carnegie Mellon University
David Turnbull

\section{3}

Sir Peter B. Hirsch

Isaac Wolfson Professor of Metallurgy, University of Oxford

1984

Walter L. Brown

Head of the Radiation Physics

Department, AT\&T Bell Laboratories

1985

John W. Cahn

Science, National Bureau of Standards

\section{6}

Minko Balkanski

Professor of Physics and Director of the Solid State Physics Laboratory,

Universite Pierre et Marie Curie

1987

Sir Charles Frank

Professor Emeritus, University of Bristol
Senior Fellow, Center of Materials

Process Products offers a series of rapid thermal modules that handle multiple processes and are available with many features. Our RTMs are capable of handling the industry's varied process requirements. For specific information on how our RTMs can be utilized for your processing needs, contact (508)689-3828 or FAX (508)686-5847.

See us at The MRS Show

Available features and capabilities include:

- Reduced Pressure (1 x 10-6 Torr)

- Mass Flow Gas Controllers

- Overpressure Activation

- I/R Temperature Sensing/Control

- Variable Ramps and Dwells

- Toxic Gas Handling

- $100 \% \mathrm{H}_{2}$ Atmosphere

- Temperature Range $100-1200^{\circ} \mathrm{C}$

- Closed Loop Control

- Ramp Rate $0.1-300^{\circ} \mathrm{C} / \mathrm{sec}$

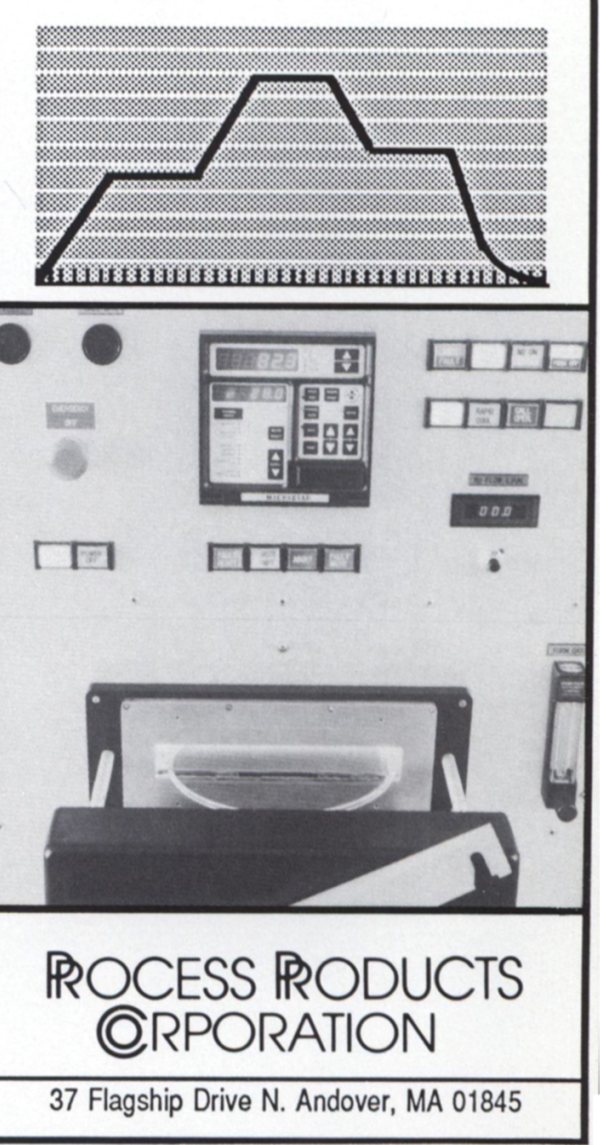

Please visit booth no. 917 at the MRS Show in Boston, November 29-December 1, 1988. 
Keeping pace with the increasing pace of change. Demands on materials researchers are growing exponentially. Yet, while the pace of change increases, there still isn't any more time in a day. And less room for error than ever.

South Bay Technology is the solution. We've helped keep research professionals just ahead of the pace of change since 1964.

SBT equipment, whether stock or custom design, brings you quickly and

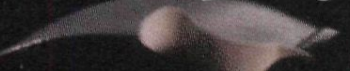

How to make light work of your toughest specimen preparation challenges.

precisely through even the most delicate specimen preparation challenges. Precision wire saws and diamond wheel saws give you an as-cut surface that will substantially reduce post-cut preparation time, even with brittle or multilayered substrate materials.

Beyond that are the finest lapping and polishing fixtures, chemical polishers, TEM specimen preparation instruments, and metallographic equipment and supplies available. All can greatly reduce sample preparation time, and many complete their tasks with the option of continual unattended operation.
A one-step solution to the mounting time problem. We've also overcome the primary cause of lost time and damaged material. The SBT Universal Mount lets you bring a specimen through every step of the preparation process, without the hazards of remounting.

The result? Large damage-free surfaces are quickly and easily reached, even down to the level required for TEM observation of undisturbed atoms.

\section{Information is power - and free -} from SBT. Find out more about how SBT can help you keep pace with the increasing pace of change. Complete the form below and mail it to SBT today. Or, for faster service, call us at (818) 442-1839. We'll rush you information about the SBT equipment that really can make lighter work of your specimen preparation challenges.

\section{SBT SOUTH BAY TECHNOLOGY inc.}

International Headquarters 5209 Tyler Avenue

Temple City, California 91780-3698 (818) 442-1839

With offices serving researchers around the world.. Australia/New Zealand, Austria/West Germany, France. Japan, China, Korea, Eastern Europe and the 